FedUni ResearchOnline

http://researchonline.federation.edu.au

This is an Accepted Manuscript of an article published by Taylor \& Francis in Tertiary Education and Management on 18/06/2008, available online: 


\title{
Studying and working: A national study of student finances and student engagement
}

\author{
Marcia Devlin \\ Richard James \\ Gabrielle Grigg
}

\section{Contact Details}

Professor Marcia Devlin

Office of the Deputy Vice Chancellor (Academic)

Deakin University

221 Burwood Highway, Burwood, Vic 3125

mdevlin@deakin.edu.au

\section{Key words}

Funding - state higher education, higher education policy/ development, national systems of higher education, student experience

\begin{abstract}
Studying and Working: A national study of student finances and student engagement

A key determinant of the new relationship between students and universities in Australia is the changing nature of higher education funding arrangements and the shift towards 'user-pays'. In 2007 Universities Australia, the peak body for universities in Australia commissioned a national study, Australian University Student Finances 2006: Final Report of a National Survey of Students in Public Universities. Drawing on the project report, this paper discusses selected findings relating to student expectations and engagement to present a worrying picture of financial duress and involvement in paid work, and examines the possible effects on the quality of higher education.
\end{abstract}





\section{Studying and Working: A national study of student finances and student engagement}

\section{Introduction}

Over the past decade, the nature of the funding arrangements for Australia's public higher education system has been slowly changing, with a swing away from public revenue towards student fees. The incremental trend towards a 'user-pays' system and the emphasis on higher education as a private good rather than public good are central elements in the new relationship between students and universities that is emerging in Australia and elsewhere - a gradual deregulation of the higher education fee environment has occurred not only in Australia but also in the UK and New Zealand. In Australia, the series of policy changes associated with fee deregulation have led to the unusual situation in which universities are now able to enrol full-fee paying domestic students alongside students whose places are government subsidised. Australian universities have become increasingly dependent on the revenue from full-fee paying students to bridge shortfalls in government funding. To date, fee-paying students have been predominantly international students and the uptake of full-fee places by domestic students has been modest, largely due to availability of government-supported places.

The gradual transfer of the burden of cost to the individual student, plus the overall rising costs of supporting oneself while at university, have altered student expectations of and engagement with university study in profound ways. This paper presents new findings on some of the issues that are arising. In early 2007, a national study of Australian university student finances (James et al. 2007) was undertaken for the Australian Vice-Chancellors' Committee (AVCC), the peak body for Australian universities (the AVCC was replaced by Universities Australia in June 2007).

The study involved a survey across all public universities of domestic students' income and expenditure, their patterns of paid employment throughout the year, and the effects of their financial circumstances on their capacity to engage with university study. This was a large, methodologically robust study, the first of its kind since 2000 and one of significant national importance and interest. The study was commissioned by the AVCC in the belief that in a changing policy and social environment it is important for the higher education sector to have data on sources of students' income and support during their university experience to inform both national and institutional policies. The findings will contribute to efforts to ensure equity and to monitor and enhance the quality of student engagement and the overall student experience.

At this point some background on the Australian higher education system might be helpful. Australia has a predominantly public higher education system in which there are 37 public universities. In the first half of 2006 there were around 860,000 students, including around 290,000 commencing students, enrolled in universities (Department of Education, Science and Training 2000, 2006). Australian higher education is well known for its innovative tuition fee arrangements. The federal government instituted the Higher Education Contribution Scheme (HECS) in 1989, designed at the time with the two-fold purpose of funding system expansion and broadening access. HECS is a deferred fee payment scheme that allows eligible students to borrow their contribution towards the cost of their tuition in a Commonwealth Supported Place (CSP) from the Government, interest-free. Graduates commence repayments, via the income taxation system, once their annual income reaches a threshold of AUD $\$ 38,148$.

In addition to Commonwealth Supported Places, Australian universities may enrol full-fee paying domestic and international students. The federal government provides assistance for living costs in the form of Austudy (for students 25 and over) and Youth Allowance (for those between 18-25). However, many students are not eligible for this support, because of the level of parental or students' own income. The income threshold for eligibility is arguably low: AUD $\$ 30,750$ for parents' joint taxable income, and no more than $\$ 535,750$ for parental assets; student income between AUD $\$ 236$ and \$316 per week means they lose 50 cents in the dollar, with income over $\$ 316$ reducing government assistance by 60 cents in the dollar. 


\section{Changing student expectations and new patterns of student engagement}

The concept of student engagement is commanding considerable attention in contemporary higher education thinking (Kuh 2003). Student engagement is generally understood as how much attention and focus students dedicate to their learning experience, "the time, energy and resources students devote to activities designed to enhance learning at university." (Krause 2007, p. 1). As Coates comments, "the concept of student engagement is based on the constructivist assumption that learning is influenced by how an individual participates in educationally purposeful activities." (2005, p. 26). Student engagement is believed to be at the heart of the quality of the educational experience - the time, financial and energy resources that a student directs towards studying are clearly directly related to the quality of that student's educational experience. It is argued that universities should seek to measure student engagement, and there are a number of questionnaires for this purpose, as engagement is a suitable proxy for student learning. For Coates, student engagement should be a central issue for institutions when they are designing their quality assurance procedures, because engagement is central to how, and how well, universities are enabling students to shape their learning experiences. Informal quality judgments made on, for example, institutional resources and reputations, do not guarantee a quality pedagogical experience, and formal quality assurance processes focus on student outcomes and teaching rather than the rapidly changing student experience (2005, p. 27-8; p. 29).

The concept of student engagement has emerged from many decades of research into higher education student learning and development. As Devlin, Coates and Kinzie (2007) note, in addition to confirming the importance of ensuring appropriate academic challenge, the higher education research has emphasised the importance of examining students' integration into institutional life and their involvement in educationally relevant experiences beyond the classroom. Measures of student engagement provide information about the extent to which individuals are making use of available educational opportunities. The importance of student engagement is clear when one considers the dimensions of engagement examined through the Australasian Survey of Student Engagement (AUSSE), a national survey that commenced in 2007. These dimensions include:

- Active Learning - students' efforts to actively construct knowledge

- Academic Challenge - the extent to which expectations and assessments challenge students to learn

- Student and Staff Interactions - the level and nature of students' contact and interaction with teaching staff

- Enriching Educational Experiences - students' participation in broadening educational activities

- Supportive Learning Environment - students' feelings of legitimate placement within the university community.

One can see that the quality of a student's educational experience is closely interlinked with the level and character of their engagement with their learning and the institutional community within which they are studying.

If the importance of student engagement is accepted, then it follows that the full range of activities and involvements that students undertake during a normal term-time week needs to be understood. What students do outside of university is of considerable importance, for this directly impinges upon the time, energy and motivation students have for their learning. And understanding the context for students' study habits takes the analysis well beyond research that looks only at the university and 'in class' experiences.

The findings of a previous national study of Australian university students conducted in 2005 show a trend towards behaviours that suggest less engagement with study (Krause et al. 2005). These behaviours include increased paid employment and many students reporting they often failed to prepare adequately for classes or missed classes. At the same time, 16 per cent of students surveyed in the 2005 study reported they did not feel they belonged to the university community (Krause et al. 2005, p. 36). 
These changing patterns of engagement are not only connected to students' financial circumstances but also to new student expectations of the higher education experience. (James 2002). The marketisation of higher education is one source of changing expectations, as it encourages higher education to be depicted as a personal investment and the student experience, and any debt accrued in the process is seen in this light. Anecdotal evidence suggests students are now more likely to expect improved services and support, such as round-the-clock access to online support. In itself these expectations are not a bad thing, assuming they are not accompanied by more passive or more dependent approaches to learning (James 2007, p. 3).

This sketch of the issues associated with student engagement and changing student expectations highlights the extent to which these are significant factors in the planning and delivery of contemporary higher education. They are deeply related to the quality of higher education and interact closely with student diversity, the new concern about the levels of first year students' readiness for higher education and the challenge of maintaining academic standards (James 2007). As James notes, Trow predicted many of the changes and pressure points now being experienced, foreseeing new patterns of studentuniversity relationships as higher education moved from elite, to mass, to universal systems (James 2007, p. 14). With Trow's forecasts now appearing broadly correct, universities face significant challenges in understanding and responding to these new relationships with students and communities, and, in particular, understanding the root causes for what appear to be low levels of engagement for many students.

\section{The purposes and methodology of the 2006 national student finances survey}

The present study provided an opportunity to examine one dimension of this situation in the Australian context, the financial situations of university students, their patterns of paid employment during term time and their attitudes towards the effects of finances and work on the quality of their university education. The purpose of the 2006 national survey was to monitor for policy purposes the financial circumstances of domestic students of Australian public universities. The project brief did not include international students, for the investigation focused on government-provided income support that is not available to fee-paying international students. The study replicated aspects of an earlier study in 2000 that was confined to undergraduate students (Long \& Hayden 2001). As well as a survey of a sample of non-Indigenous students, a population survey was conducted for Indigenous students, using a slightly modified instrument. These latter findings of the survey are not reported here.

The survey method was designed to ensure reliable data were collected with which to inform policy. A nationally representative stratified sample of students was chosen from all public universities. A sample of sufficient size was created to ensure statistical power, suitable cell sizes for conducting subgroup analyses and credibility of the findings with stakeholders. Postgraduate students were sampled across coursework and research higher degree programs. The survey was conducted by mail in the second semester, 2006, with respondents posting their surveys voluntarily and anonymously to a commercial mail house. A second mailout a few weeks after the first mailout of surveys was used to improve the response rate.

The design of the sampling was based on an estimate of a total of 530,000 undergraduates and 175,000 postgraduate domestic students. Once forms with obvious errors were excluded, the number of responses was 18,954, representing 2.7 per cent of Australia's domestic higher education students. The demographic characteristics of these responses indicate a close match to those of the national domestic student population as a whole. The response rates by institution were mostly between 17 and 23 per cent, with three atypical response rates: a low of 9.9 per cent and highs of 30.1 and 28.9 per cent.

The survey data include quantitative information from responses to Likert scales and dollar estimates of various aspects of income and expenditure as well as qualitative information collected from open-ended questions. The latter data are highly important to the interpretation of the quantitative data and to developing an understanding of the impact of students' financial circumstances, debt and patterns of work on their engagement with university study. 


\section{The findings on the financial circumstances of Australian university students}

\section{Many students experience financial hardship}

The broad conclusion to be drawn from the data is one of student financial duress. Many students reported budget deficits, painstaking budgeting and a reliance on paid employment to cover basic living costs. Many students wrote of the difficulty in prioritising expenditure, weighing up, for example, whether to purchase textbooks or adequate food. The situation for many students can be summarised as follows: low to modest incomes, mounting debt, limited access to government assistance and reliance on 'gifts' from family and friends. These factors combine to produce a picture of financial hardship that appears to have worsened slightly since the 2000 study. As Table 1 shows, students' reported total annual incomes that are in many cases low (for comparison, in July 2007, AUD $\$ 100=$ US $\$ 85$ ).

Table 1 Total annual income, grouped, all students (AUD\$)

\begin{tabular}{|c|c|c|c|c|c|c|c|c|}
\hline & \multicolumn{3}{|c|}{$\begin{array}{l}\text { Undergraduate } \\
\text { students }\end{array}$} & \multicolumn{5}{|c|}{$\begin{array}{l}\text { Postgraduate } \\
\text { students }\end{array}$} \\
\hline & \multirow[b]{2}{*}{ F-T } & \multirow[b]{2}{*}{ P-T } & \multirow[b]{2}{*}{ All } & \multicolumn{2}{|c|}{ Research } & \multicolumn{2}{|c|}{ Coursework } & \multirow[t]{2}{*}{ All } \\
\hline & & & & F-T & P-T & F-T & P-T & \\
\hline Under $\$ 10,000$ & 41.8 & 12.2 & 35.9 & 6.5 & 6.9 & 32.4 & 7.3 & 10.9 \\
\hline$\$ 10,000$ to $\$ 19,999$ & 42.7 & 20.4 & 38.2 & 15.3 & 13.6 & 31.0 & 7.5 & 13.2 \\
\hline$\$ 20,000$ to $\$ 29,999$ & 11.1 & 20.5 & 13 & 46 & 12.3 & 15.0 & 9.7 & 17.3 \\
\hline$\$ 30,000$ to $\$ 39,999$ & 2.8 & 21.1 & 6.5 & 20.7 & 15.4 & 8.5 & 18.9 & 17.2 \\
\hline$\$ 40,000$ and over & 1.5 & 25.8 & 6.4 & 11.5 & 51.8 & 13.1 & 56.6 & 41.4 \\
\hline
\end{tabular}

(Reproduced from James et al. 2007, p. 13)

While the average undergraduate income increased from $\$ 12,513$ to $\$ 16,020$ (28.1 per cent) between 2000 and 2006, it increased only by 8.2 per cent in real terms (based on a Consumer Price Index rise of 18.4 per cent between 2000 and 2006), with this rise in overall income mostly due to paid employment. Students received less from, for example, the Government Youth Allowance scheme (a decrease of a mean of \$2419 in 2000 to $\$ 2160$ in 2006), and fewer students were eligible for government assistance. While a similar number of full-time undergraduates (29.7 per cent in 2000; 30.4 per cent in 2006) received Youth Allowance, far fewer received Austudy (a decrease from 12.7 per cent in 2000 to 4.8 per cent in 2006). Overall, the number of full-time undergraduates receiving either Austudy or Youth Allowance fell from 42.4 per cent in 2000 to 35.2 per cent in 2006.

Overall, students are earning more in paid employment than in the past, but are receiving less government assistance. Further, as noted in the project report:

Comparison of the 2000 and 2006 undergraduate samples suggests a link between the decrease in availability of government income support and the increase in students relying on non-cash assistance and cash gifts. Among full-time undergraduate students, there was a 12.3 per cent increase in the number of students relying on free meals; a 20.7 per cent increase in the number relying on free accommodation, and a 71.0 per cent increase in the number relying on gifts of text books ... Taken together, the increase in reliance on gifts of food and other necessities, the decrease in availability of government income support, and the increase in the contribution of income from paid employment, point to a significant shift in responsibility for student income away from public support and toward private support (James et al. 2007, p. 20).

\section{Students are, on average, working long hours}

The typical Australian student is a working student who spends substantial time in paid employment each week. In total, 72.3 per cent of undergraduates were employed during semester, a slight downward trend from 2000 (76 per cent); however a higher proportion reported having been employed in the last 12 months (85.1 per cent in 2006, and 78.1 per cent in 2000). At undergraduate level, 16.5 per cent of full-time students in employment worked at least 20 hours per week during semester. Time 
spent in employment is particularly an issue at postgraduate level: 38.2 per cent of coursework students and 32.0 per cent of research students reported working in excess of 20 hours per week.

Even those working less than 20 hours a week still reported substantial time commitments: the mean hours for full-time undergraduate and postgraduate research students were between 13 and 17 hours a week; full-time postgraduate students reported working mean hours of between 17 and 24 hours per week, while part-time students in employment typically spent between 30 and 40 hours per week in paid employment. Previous studies indicate students spending similar amounts of hours in paid employment: the present study's finding of a mean of 14.8 hours paid employment per week during semester for full-time undergraduate students compares with the mean reported by Krause et al. (2005) of 12.5 hours for full-time first year students and the mean reported by Long and Hayden (2001) of 14.5 hours for full-time undergraduates. 16.4 per cent of full-time students undertaking paid employment worked in two workplaces each week, indicating a degree of casualisation of their paid work.

\section{Students are not merely working to fund a lifestyle}

There has been speculation that university students are motivated to work these days due to lifestyle aspirations. There is little evidence in the study's data to support this belief. Indeed, the indications are that most working students are working simply to provide for everyday needs. In addition, the study indicates that the distribution of students' costs is heavily weighted towards the basics of rent, food and household expenses, and trending upwards (see Table 2 below). Reported personal costs have been falling since 1984 while transport and study-related costs are increasing.

Table 2 Distribution of full-time undergraduate student expenses (\%)

\begin{tabular}{|c|c|c|c|c|c|}
\hline & 1974 & 1979 & 1984 & 2000 & 2006 \\
\hline Rent, food, household & 43 & 40 & 34 & 31 & 35 \\
\hline Transport & 24 & 24 & 16 & 22 & 21 \\
\hline Personal costs & 23 & 26 & 42 & 35 & 33 \\
\hline Study-related costs & 10 & 10 & 9 & 10 & 12 \\
\hline
\end{tabular}

(Adapted from Long \& Hayden 2001)

Some students experience extreme hardship: 14.1 per cent of undergraduates and 8.5 percent of postgraduates surveyed reported regularly going without food and other necessities because they could not afford them. One student said:

When I left home and became a full-time psychology student I found it very difficult to find money for food and clothes. All of my youth allowance went on bills and I had to ask people for food or if they could give me some money for food - it was a really humiliating situation. (female, part-time postgraduate)

\section{Some effects of students' paid employment on their studies}

The constraints and pressures of the financial situations described above are affecting students' outlooks and actions. A rising proportion are concerned about their financial situation and the effect of financial difficulties on their capacity to study; many feel that they must make stressful choices between prioritising their resources of time, energy and money, for the time spent on study reduces the time to earn money to spend on living costs.

One quarter of the undergraduates who were working reported regularly missing classes or equivalent activities because of employment commitments. Unsurprisingly perhaps, far more part-time students ( 37.4 per cent) missed work for classes than full-time students $(22.7$ per cent). The proportion of students skipping classes for work appears to be rising: in the 2000 study, 6 per cent of students reported 'frequently' missing classes while in the 2006 study, 10 per cent of full-time undergraduates 'strongly agreed' that they regularly missed classes/study commitments. Among working postgraduates, the comparable figures on the proportion of students missing classes for work were 26.7 per cent of all students. When this aggregate figure is broken down significant patterns of difference 
emerge: 16.4 per cent of full-time research students; 35.6 per cent of part-time research students, 25.3 per cent full-time coursework students and 27.7 per cent of part-time coursework students reported skipping class, the first figure likely to reflect the availability of income support for full-time research higher degree candidates.

Table 3 also shows that paid employment and poverty are reasons for students missing classes that combine with one another: a number of students literally cannot afford to go to class if there is the opportunity for work.

Table 3 Reasons for regularly missing study commitments (proportion who agree or strongly agree with proposition)

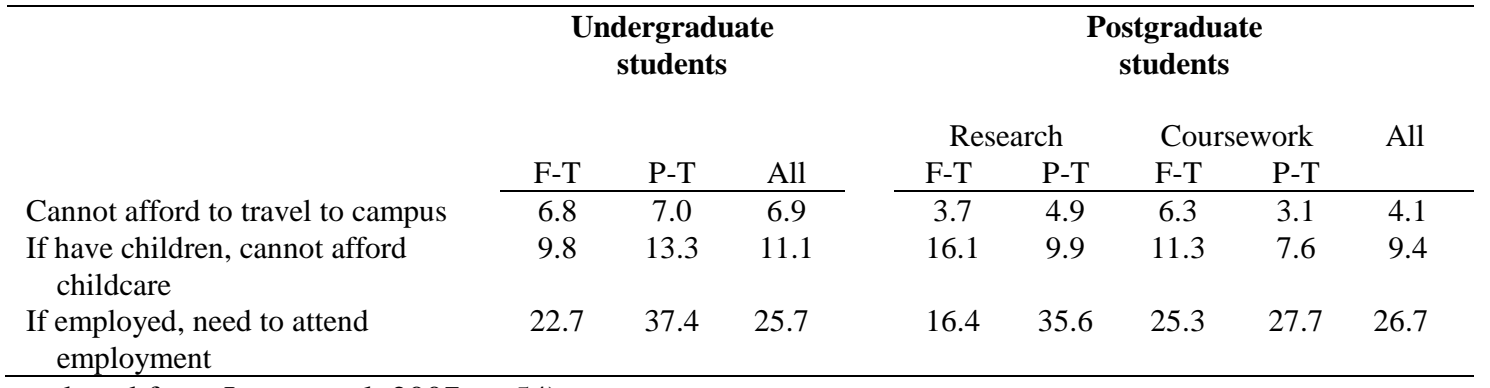

(Reproduced from James et al. 2007, p. 54)

Student involvement in paid work affects the quality of their study: 43.1 per cent of employed undergraduates and 47.7 per cent of employed postgraduates reported that their work adversely affected their study. Students appear to be increasingly concerned about the impact of paid employment on their studies. In 2006, 18 per cent of full-time undergraduates in paid work 'strongly agreed' that their 'work commitments adversely affect [their] performance in university', an increase on the 2000 results in which 15 per cent of full-time undergraduates in paid work reported that it affected their studies 'a great deal'.

The qualitative data highlight the effects of paid work on the quality of students' educational experience:

It is very difficult to maintain a high level of university work when you must work to support yourself. I am often exhausted as out of necessity much of my 'free' 'non work' time (evenings, weekends) is taken up with study, homework, assignments. I get no free time as everything is highly structured to finish the work. (female, part-time undergraduate)

Student comments related to managing work and study show that universities may need to rethink notions of flexibility of access:

University never takes into account the fact that some students have to work casual employment in order to live. The lecturers and tutors have no flexibility for this and this has been the cause of a lot of grief for me during my studies (female, full-time undergraduate)

Many students were concerned that their courses did not provide for the flexibility they needed to fit in with their paid employment and in some cases the work placement expectations of their courses:

It is extremely difficult during teaching rounds (9 weeks) of the year to make ends meet without a large amount of stress as you are required full time at the school and also need to work on top of this. (female, full-time postgraduate)

The effects on the quality of education when classes and other study commitments are regularly missed do not only apply to the individual students who are forced to choose paid work over study, as this student explains: 
Many of my fellow students have to work - they miss classes and are often stressed. This can be difficult when they are in groups for assignments - sometimes they do not have the time to put in the effort and the other students suffer. (female, full-time undergraduate)

The cost of childcare was a concern for a sizeable portion of students with children, with 11.1 per cent of undergraduates and 9.4 per cent of postgraduates (including, most notably, 16.1 per cent of full-time research students) surveyed responding that not being able to meet the expenses of childcare regularly prevented them from attending classes. Transport expenses also prevented students (6.9 per cent undergraduate and 4.1 per cent postgraduate respondents) from regularly attending classes. The cost of transport can be problematic:

... travelling fuel is very expensive. To go to uni costs me at least $\$ 90$ per week...No public transport is available to the university from my area. (Indigenous female, full-time undergraduate)

\section{The implications of the findings: Responding to the new character of student lives}

This study provides a snapshot of the contemporary student experience in Australian higher education, captured from the perspective of student finances. The study did not attempt to answer in full the questions around new student expectations and changing patterns of engagement. It does, however, show that even on the simplest analysis a substantial degree of student 'disengagement' can be traced to the demands of paid employment during term time. The student finances study suggests that Australian students may not be actively choosing to 'disengage' but do so due to financial circumstances beyond their control as they focus on covering the costs of basic necessities. Students appear compelled to trade off the time available for study to meet their living costs - many find this to be an insidious equation in which long-term benefit is sacrificed to short-term necessity.

If a high proportion of students is having an impoverished educational experience at university, there are possible ramifications for the emerging generation of graduates and thus for society as a whole. National and institutional policy-making needs to engage with these issues, for they are a significant element in the overall quality of higher education. What steps might be taken? Clearly, improved student income support at a national level is needed, perhaps along the lines of a deferred repayment scheme such as is successfully in place with the Higher Education Contribution Scheme (HECS).

But a wider response is also needed. The working student is likely to be a reality for universities regardless of the levels and availability of income support. Students also choose to work as a result of emerging values and trends in society at large, which influence students before they arrive at university. The blurring of study and work, and complex patterns of people entering and re-entering higher education programs are inevitable in mass/universal systems - for a range of reasons, people expect to be able to work while studying (and equally to study while working) and are likely to expect that the possibility of combining paid work with study should be facilitated by government and institutions. The traditional idea of a linear school, university, work progression, which still informs much policy and practice in higher education, no longer holds true.

Universities may need to look more closely at the expectations of students and the factors that are shaping these; further, universities may benefit from exploring ways to exert greater influence over the nature of student expectations rather than merely reacting to them. The needs of the working student, now in a clear majority, are a central consideration but not the only one.

Most universities appear to operate for administrative purposes on the concept of full-time and parttime students; however, this simple dichotomy does not align well with the more diverse character of the educational experience - the student finances study data suggest almost as much variation within the two groups as between them. It is perhaps time to consider that the idea of the full-time student should no longer inform higher education delivery and to redesign timetabling, campuses, online access, the curriculum and work-study integration for the new breed of students and the social and 
economic context in which they are studying.

Of course, flexible learning and distance learning have long been viewed as options for people who are unable to attend campus in conventional full-time fashion. But these modes of delivery arguably have not met the high expectations of widening access and broadening participation. Nonetheless, revisiting the flexibility of the curriculum and looking for new ways to foster student engagement via curriculum design and work placements is worth examining (James 2007, p. 11; Krause 2007, p. 9; Yorke 2007).

To achieve a new level of flexible engagement is a tall order that would require a paradigm shift for many institutions. In addition, such a change in thinking would need to be supported by government policy, as there would be numerous equity and implementation issues to be worked through. For example, there is a certain appeal in the idea of integrating paid work placements into courses of study, but there are also many practical considerations. It is likely that some disciplines or fields of study would more easily introduce or accommodate such schemes than others, which may lead to equity issues if certain students or student groups have more favourable work/study conditions than others. The closer alignment of academia and work may also have long-term undesirable effects on the independence of universities and their curricula.

\section{Concluding remarks}

The incremental transfer of the cost burden of higher education to the individual student is having a significant impact on the student experience. As students struggle to meet this burden through increasing hours of paid work, there is evidence that the quality of their engagement with university, and the quality of their education broadly, appear to be compromised as a result. If such a pattern is as widespread elsewhere as the data from this Australian sample suggest, this will ultimately affect both the private and public good that can result from higher education and the 'savings' made by governments who have moved toward user-pays systems may turn out to be somewhat costly in the longer term.

\section{The authors}

Dr Marcia Devlin (mdevlin@unimelb.edu.au) and Professor Richard James (r.james@unimelb.edu.au) are higher education researchers in the Centre for the Study of Higher Education at the University of Melbourne. Gabrielle Grigg is a PhD candidate in the Centre.

\section{Acknowledgement}

The authors thank University of Melbourne colleagues Ms Emmaline Bexley and Professor Simon Marginson who co-authored the national study on which this paper is based.

\section{References}

Coates, H. (2005). The nature of student engagement for higher education quality assurance, Quality in Higher Education 11, 25-36.

Department of Education, Science and Training (2000-2006). Higher Education Students Time Series Tables: Selected Higher Education Statistics.

Accessed 17/07/07 from:

http://www.dest.gov.au/sectors/higher_education/publications_resources/statistics/publications_higher_ education_statistics_collections.htm

Devlin, M., Coates, H. and Kinzie, J. (2007). Using AUSSE data for enhancement. Australian Council for Educational Research, Melbourne, Australia.

James, R. (2007). Students and Student Learning in Mass Systems of Higher Education: Six Educational Issues Facing Universities and Academic Leaders. Paper prepared for the seminar series, Mass Higher Education in UK and International Contexts, Surrey, UK, 29-30 May 2007. 
James, R., Bexley, E., Devlin, M. \& Marginson, S. (2007). Australian University Student Finances 2006: Final Report of a National Survey of Students in Public Universities. Canberra: Australian ViceChancellors' Committee.

James, R. (2002). Students' changing expectations of higher education and the consequences of mismatches with reality. In P. Coaldrake (ed.) Responding to Student Expectations. Paris: OECD.

Krause, K., Hartley, R., James, R. \& McInnis, C. (2005). The First Year Experience in Australian Universities: Findings from a Decade of National Studies. Canberra: Department of Education, Science and Training.

Krause, K. (2005). Engaged, Inert, or Otherwise Occupied? Deconstructing the $21^{\text {st }}$ Century Undergraduate Student. Keynote delivered at the James Cook University Symposium, Sharing Scholarship in Learning and Teaching: Engaging Students, James Cook University, Townsville/Cairns, Queensland. 21-22 September 2005.

Krause, K. (2007). New Perspectives on Engaging First Year Students in Learning. Brisbane: Griffith Institute for Higher Education.

Kuh, G. D. (2003). What we're learning about student engagement from NSSE: benchmarks for effective educational practices, Change 35, 24-32.

Long, M. \& Hayden, M. (2001). Paying Their Way: A Survey of Australian Undergraduate University Student Finances. Canberra: AVCC.

Yorke, M. (2007, 29 June). Learning on the job should be part of studying, The Times Higher Education Supplement, p. 14. 